\title{
Enzymatic depolymerization of gum Tragacanth: Bifidogenic potential of low molecular weight oligosaccharides
}

\author{
Ahmadi Gavlighi, Hassan; Michalak, Malwina; Meyer, Anne S.; Mikkelsen, Jørn Dalgaard
}

Published in:

Journal of Agricultural and Food Chemistry

Link to article, DOI:

$10.1021 / \mathrm{j} f 304795 f$

Publication date:

2013

Document Version

Publisher's PDF, also known as Version of record

Link back to DTU Orbit

Citation (APA):

Ahmadi Gavlighi, H., Michalak, M., Meyer, A. S., \& Mikkelsen, J. D. (2013). Enzymatic depolymerization of gum Tragacanth: Bifidogenic potential of low molecular weight oligosaccharides. Journal of Agricultural and Food Chemistry, 61, 1272-1278. https://doi.org/10.1021/jf304795f

\section{General rights}

Copyright and moral rights for the publications made accessible in the public portal are retained by the authors and/or other copyright owners and it is a condition of accessing publications that users recognise and abide by the legal requirements associated with these rights.

- Users may download and print one copy of any publication from the public portal for the purpose of private study or research.

- You may not further distribute the material or use it for any profit-making activity or commercial gain

- You may freely distribute the URL identifying the publication in the public portal 


\title{
Enzymatic Depolymerization of Gum Tragacanth: Bifidogenic Potential of Low Molecular Weight Oligosaccharides
}

\author{
Hassan Ahmadi Gavlighi, ${ }^{\dagger} \S^{\S}$ Malwina Michalak, ${ }^{\dagger}$ Anne S. Meyer, ${ }^{* \dagger}$ and J. Dalgaard Mikkelsen ${ }^{\dagger}$ \\ ${ }^{\dagger}$ Center for Bioprocess Engineering, Department of Chemical and Biochemical Engineering, Technical University of Denmark \\ (DTU), DK-2800 Kgs. Lyngby, Denmark \\ ${ }^{\S}$ Department of Food Science and Technology, Faculty of Agriculture, Tarbiat Modares University, P.O. Box 14115-336, Tehran, Iran
}

\begin{abstract}
Gum tragacanth derived from the plant "goat's horn" (Astragalus sp.) has a long history of use as a stabilizing, viscosity-enhancing agent in food emulsions. The gum contains pectinaceous arabinogalactans and fucose-substituted xylogalacturonans. In this work, gum tragacanth from Astragalus gossypinus was enzymatically depolymerized using Aspergillus niger pectinases (Pectinex BE Color). The enzymatically degraded products were divided into three molecular weight fractions via membrane separation: HAG1 < $2 \mathrm{kDa} ; 2 \mathrm{kDa}<\mathrm{HAG} 2<10 \mathrm{kDa}$; HAG3 > $10 \mathrm{kDa}$. Compositional and linkage analyses showed that these three fractions also varied with respect to composition and structural elements: HAG1 and HAG2 were enriched in arabinose, galactose, and galacturonic acid, but low in fucose and xylose, whereas HAG3 was high in (terminal) xylose, fucose, and 1,4-bonded galacturonic acid, but low in arabinose and galactose content. The growth-stimulating potential of the three enzymatically produced gum tragacanth fractions was evaluated via growth assessment on seven different probiotic strains in single-culture fermentations on Bifidobacterium longum subsp. longum (two strains), B. longum subsp. infantis (three strains), Lactobacillus acidophilus, B. lactis, and on one pathogenic strain of Clostridium perfringens. The fractions HAG1 and HAG2 consistently promoted higher growth of the probiotic strains than HAG3, especially of the three B. longum subsp. infantis strains, and the growth promotion on HAG1 and HAG2 was better than that on galactan (control). HAG3 completely inhibited the growth of the $C$. perfringens strain. Tragacanth gum is thus a potential source of prebiotic carbohydrates that exert no viscosity effects and which may find use as natural functional food ingredients.
\end{abstract}

KEYWORDS: gum tragacanth, molecular size, prebiotic potential, enzymatic modification, Bifidobacterium longum subsp. infantis

\section{INTRODUCTION}

There is an increasing interest in the development and identification of new carbohydrates having prebiotic effects. Prebiotic carbohydrates are defined as selectively fermented compounds that cause specific probiotic changes in the gastrointestinal microbiota (currently mainly understood as stimulating the growth of lactobacilli and bifidobacteria), which in turn confer benefits upon the well-being and health of the host. ${ }^{1,2}$ The beneficial growth stimulation of specific probiotic colonic bacteria is generally explained by the capability of these bacteria to cleave the glycosidic linkages in the prebiotic carbohydrates. A primary example of natural prebiotics is the group of human milk oligosaccharides, which constitutes a structurally diverse family of galactose-, glucose, $\mathrm{N}$-acetylglucosamine, sialic acid, and fucose-substituted lactose-based structures containing different types of glycosidic linkages, and which are almost unique to human breast milk. Human milk oligosaccharides were thus originally recognized as being responsible for the "bifidus factor" of human milk and involved in the relationship between the intestinal bacteria and lower incidences of infectious diarrhea in breast-fed infants. ${ }^{3}$ Galactooligosaccharide (GOS) and fructo-oligosaccharide (FOS) are two main types of oligosaccharides that are recognized as prebiotics and which have been tested in human trials and which are already available on the market. ${ }^{4,5}$ Foods containing these compounds are generally categorized as functional foods. ${ }^{6}$

Gum tragacanth is an exudate from the stem of the bushlike plant "goat's-horn", Astragalus species, and is one of the few natural plant sources of L-fucose-substituted polysaccharides. The gum has been used commercially for well over 2000 years, is approved for food use in both the United States and Europe, ${ }^{7,8}$ and is widely used as an emulsifier and thickener in emulsion systems in different food, pharmaceutical, and cosmetic applications. ${ }^{9}$

Gum tragacanth is made up of highly substituted, heterogeneous hydrophilic polysaccharides containing Larabinose, D-galactose, D-glucose, D-xylose, L-fucose, L-rhamnose, and D-galacturonic acid and confers high viscosity when in aqueous solution. ${ }^{10}$ When solubilized in water, the gum is usually categorized in a "soluble" fraction, tragacanthin, and an "insoluble" fraction, bassorin, respectively. ${ }^{11}$ The water-soluble tragacanthin fraction appears to resemble pectin and contains linear chains of galacturonic acid (probably 1,4- $\alpha$-linked) and arabinogalactan structures ${ }^{12}$ as well as fuco-xylogalacturonans, whereas bassorin is believed to be mainly composed of a mixture of xylo- and fuco-xylo-substituted polysaccharides. ${ }^{11}$ Terminal fucosyl residues are also found in some human milk oligosaccharide structures (as $\alpha 1-2, \alpha 1-3$, and $\alpha 1-4$ substitutions); hence, gum tragacanth saccharides could have prebiotic effects mainly because of the L-fucose-substituted polysaccharides. However, the high viscosity inducing effects of

Received: November 15, 2012

Revised: January 19, 2013

Accepted: January 23, 2013

Published: January 23, 2013 
gum tragacanth partly prevent unfolding of this potential, because the viscosity means that only low levels are used, because inclusion of even very low levels of gum tragacanth in food products changes the physicochemical properties of the products significantly.

Recently, enzyme technology has been used to produce various potentially prebiotic oligo- and polysaccharides from plant fiber polysaccharides for food applications. ${ }^{13-15}$ In particular, the combination of enzymatic depolymerization of various natural polysaccharides and membrane reactor separation has proven useful for lowering the viscosity of hydrocolloid polysaccharides and for obtaining prebiotic compounds of different molecular sizes and structural compositions. $^{6,16,17}$ In these previous studies it has been shown that both the molecular size and the structural makeup of the resulting poly- and oligosaccharides have a significant influence on their potential prebiotic bacterial growth promoting properties. ${ }^{13,14,18}$

The hypothesis driving the present work was that gum tragacanth, notably via its content of highly fucose-substituted xylo-galacturonans, could be a new, natural source of putatively food grade prebiotics. A second hypothesis was that the gum tragacanth could be processed into differently sized poly- and oligosaccharide fractions via enzymatic treatment and membrane purification.

The aim of this work, therefore, was three-fold: (A) to investigate whether pectinase-catalyzed depolymerization of tragacanth gum could reduce the viscosity of the gum in solution and allow separation of the products into different molecular sizes via membrane filtration; (B) to investigate whether the resulting fuco-xylooligosaccharides (FXO) from this gum had potential growth-stimulating effects on selected gut-relevant bacteria, and (C) to evaluate whether the molecular size and/or composition, structure, and type of linkages of the enzymatically produced gum tragacanth polysaccharides would influence their prebiotic potential.

\section{MATERIALS AND METHODS}

Materials. The gum tragacanth sample, Astragalus gossypinus, was selected for this work because of its particularly high fucose content. ${ }^{8,11}$ Hence, the gum tragacanth derived from A. gossypinus was recently found to contain $\sim 235 \mathrm{mg}$ fucose/g dry matter, whereas the fucose contents in other gum tragacanth samples obtained from five other species of Iranian Astragalus bush plants were found to range from 30 to $115 \mathrm{mg} / \mathrm{g}$ dry matter. ${ }^{8}$ The dried raw gum was ground using an $\mathrm{OBH}$ Nordica coffee mill (OBH Nordica A/S, Copenhagen, Denmark) to pass through a $500 \mu \mathrm{m}$ sieve. Dextran standards with molecular weights of 10,40 , and $110 \mathrm{kDa}$ were from Pharmacia (Uppsala, Sweden). Pullulan standards with molecular weight sof 1.3 and $400 \mathrm{kDa}$, and L-fucose, L-rhamnose, D-arabinose, D-galactose, Dglucose, D-xylose, and D-galacturonic acid were obtained from SigmaAldrich Chemical Co. (St. Louis, MO, USA). Trifluoroacetic acid (TFA) (99\%) was from Merck (Darmstadt, Germany). Sodium hydroxide $(\mathrm{NaOH})$ standard solution of HPLC grade was from SigmaAldrich Chemical Co.

Enzyme. Pectinex BE Color, $3600 \mathrm{MOE}$ units $/ \mathrm{mL}$, pH optimum 3.5-4.0, temperature optimum $45-55{ }^{\circ} \mathrm{C}$, was obtained from Novozymes A/S (Bagsværd, Denmark). This enzyme preparation is derived from Aspergillus niger, mainly contains pectin lyase and polygalactronase activity, and is approved as a processing aid for industrial food applications. ${ }^{19}$

Enzymatic Digestion and Membrane Separation of Gum Tragacanth. Tragacanth gum $(10 \mathrm{~g} / \mathrm{L})$ was dissolved in deionized water (4 L, Milli-Q water) during stirring for $2 \mathrm{~h}$ at room temperature $\left(22^{\circ} \mathrm{C}\right)$. After the tragacanth gum solution had been heated to $50{ }^{\circ} \mathrm{C}$, using a Sartorius Biostat heating cap setup, $10 \mathrm{~mL}$ of Pectinex BE
Color enzyme (equivalent to the addition of $9000 \mathrm{MOE}$ units/L) was added, and after $2 \mathrm{~h}$ of reaction, when the viscosity of the solution had dropped from 1.2 to $0.57 \mathrm{~Pa} \cdot \mathrm{s}$, continuous filtration of the enzymatically treated gum tragacanth solution was initiated by using a cross-flow Hydrosart $10 \mathrm{kDa}$ membrane (Millipore, Sartorius). This filtration was continued overnight $(18 \mathrm{~h})$. The initial viscosity drop to $\sim 0.6 \mathrm{~Pa} \cdot \mathrm{s}$ was not used to evaluate the hydrolysis (as the viscosity will of course vary with the initial concentration of the suspended gum tragacanth as well as with the shear shear rate employed ${ }^{8}$ ), but was simply a prerequisite for initiating the membrane fractionation to obtain differently sized molecules. After the first overnight filtration, the retentate was heated to $100{ }^{\circ} \mathrm{C}$ for $10 \mathrm{~min}$ to halt the enzyme reaction. This retentate $(\sim 1 \mathrm{~L})$ was defined as HAG3 $>10 \mathrm{kDa}$. The permeate $(\sim 3 \mathrm{~L})$, that is, the enzymatically degraded product, was then separated further using another cross-flow Hydrosart membrane setup with a $2 \mathrm{kDa}$ membrane; this second filtration was stopped after collection of $\sim 1.5 \mathrm{~L}$ of permeate, and this permeate was designated HAG1; the retentate remaining was designated HAG2. Finally, the three collected fractions (HAG1 $<2 \mathrm{kDa} ; 2 \mathrm{kDa}<\mathrm{HAG} 2<10 \mathrm{kDa}$; and HAG3 $>10 \mathrm{kDa}$ ) were freeze-dried and stored frozen at $-20{ }^{\circ} \mathrm{C}$ until further analysis and microbial growth testing.

Compositional Analysis. The monosaccharide composition of the A. gossypinus gum tragacanth starting material and of the membrane-separated products from the enzymatic reaction were determined after TFA hydrolysis $\left(2 \mathrm{M}, 2 \mathrm{~h}, 121{ }^{\circ} \mathrm{C}\right)^{20}$ by using an ICS3000 ion chromatography system equipped with a CarboPacTM PA20 (3 mm $\times 150 \mathrm{~mm}$ ) analytical column (Dionex Corp., Sunnyvale, CA, USA), using an elution program described previously. ${ }^{8}$

Molecular Weight Distribution (HPSEC). The lyophilized fractions from the membrane filtration and the gum tragacanth starting material were dissolved in $0.1 \mathrm{M}$ sodium acetate buffer

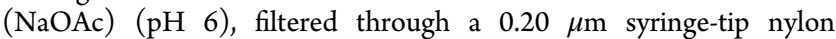
membrane filter (VWR International, USA), separated for highperformance size exclusion chromatography on a Shodex OHpak SB$806 \mathrm{HQ}(8.0 \mathrm{~mm} \times 300 \mathrm{~mm})$ column (Showa Denko KK, Kawasaki, Japan), and eluted with $0.1 \mathrm{M} \mathrm{NaOAc}(\mathrm{pH} 6)$ at a flow rate of $0.5 \mathrm{~mL} /$ min at $30{ }^{\circ} \mathrm{C}$ on a system consisting of a P680 HPLC pump and an ASI-100 automated sample injector using a refractive index detector Shodex RI-101 (Showa Denko KK). The injection volume was $25 \mu \mathrm{L}$. The column was calibrated with Pharmacia Dextran (T10, T40, and T110 kDa) and pullulan (1.3 and $400 \mathrm{kDa})$ as standards. ${ }^{21}$

Linkage Analysis. To improve the hydrolysis and detection of uronic acids as alditol acetates, the uronic acids in each sample were activated by carbodiimide activation and subsequently reduced prior to permethylation according to the procedure of Kim and Carpita ${ }^{22}$ as follows: Carbodiimide activation was accomplished by adding $0.25 \mathrm{~g}$ of l-cyclohexyl-3-(2-morpholinoethyl)carbodiimide metho- $p$-toluenesulfonate per $\sim 1.5 \mathrm{mg}$ of sample suspended in sodium acetate at $\mathrm{pH}$ $4.6(2-3 \mathrm{~mL})$. The activated uronic acids were then reduced using sodium borodeuteride $\left.\left(\mathrm{NaBD}_{4}\right)\right)^{22}$ The samples were then dialyzed to desalt and then lyophilized. The methylation was then done according to the method of Ciucanu and Kerek ${ }^{23}$ with the addition of dimethyl sulfoxide (DMSO) $(1 \mathrm{~mL})$ to the dried samples, followed by $\mathrm{NaOH}$ addition (200 mg in $1 \mathrm{~mL}$ of dry DMSO). After $15 \mathrm{~min}$, methyl iodide $\left(\mathrm{CH}_{3} \mathrm{I}\right)$ was added, and the reaction mixture was left for $45 \mathrm{~min}$. To prevent undermethylation, one more round of $\mathrm{NaOH}$ addition (15 min) and $\mathrm{CH}_{3} \mathrm{I}$ addition (45 min) was done. The samples were then hydrolyzed using $2 \mathrm{M}$ TFA ( $2 \mathrm{~h}$ at $121{ }^{\circ} \mathrm{C}$ in sealed tubes), reduced with $\mathrm{NaBD}_{4}$, and acetylated using acetic anhydride/trifluoroacetic acid. Finally, the resulting, partially methylated alditol acetates (PMAAs) were analyzed by gas chromatography-mass spectrometry (GC-MS) ${ }^{24}$ by separation on a $30 \mathrm{~m}$ RTX 2330 bonded phase fused silica capillary column on an Agilent6890N GC interfaced to a 5975B MSD (mass selective detector, electron impact ionization mode).

Bacterial Strains and Growth Conditions for Single-Culture Fermentations. The bacterial strains were Bifidobacterium longum subsp. longum (Danisco Global Culture Collection DGCC 232), B. longum subsp. infantis (DGCC 233), B. longum subsp. infantis (DGCC 1497), B. longum subsp. infantis (DGCC 2238), Lactobacillus acidophilus (NCFM, ATCC 700396), B. longum subsp. longum (Bl- 


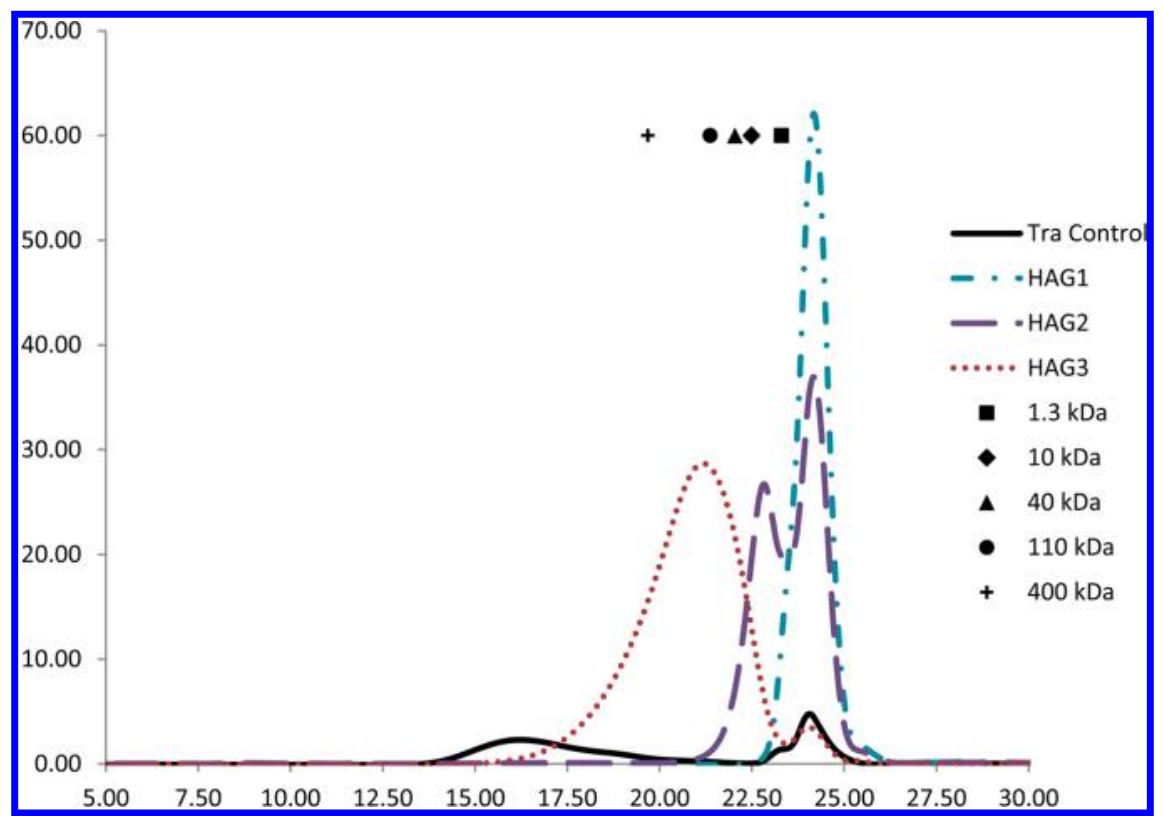

Figure 1. Molecular size profiles of gum tragacanth samples of different molecular sizes (HAG1 < 2 kDa; 2 kDa $<$ HAG2 < 10 kDa; and HAG3 > 10 $\mathrm{kDa}$ ), obtained after enzymatic modification and membrane separation. "Tra Control" indicates the track of the original gum tragacanth starting material.

Table 1. Tragacanth Gum, A. gossypinus, Monosaccharide Composition of Different Molecular Size Fractions (HAG1 < 2 kDa; 2 kDa < HAG2 < $10 \mathrm{kDa}$; and HAG3 > $10 \mathrm{kDa}$ ), Obtained after Enzymatic Modification and Membrane Separation ${ }^{a}$

\begin{tabular}{|c|c|c|c|c|}
\hline sugar composition (mg/g dry matter) & A. gossypinus ${ }^{b}$ & HAG1 & HAG2 & HAG3 \\
\hline fucose & $236 \pm 5 b$ & $25.5 \pm 2.7 \mathrm{~d}$ & $102 \pm 6 c$ & $296 \pm 3 a$ \\
\hline rhamnose & $16.0 \pm 4.2 c$ & $31.5 \pm 4.3 b$ & $65.3 \pm 1.4 \mathrm{a}$ & $2.8 \pm 0.6 \mathrm{~d}$ \\
\hline arabinose & $48.1 \pm 2.4 c$ & $293 \pm 2 a$ & $130 \pm 1 b$ & $32.2 \pm 0.6 \mathrm{~d}$ \\
\hline galactose & $38.9 \pm 1.7 \mathrm{c}$ & $123 \pm 10 a$ & $83.7 \pm 0.9 b$ & $8.9 \pm 0.0 \mathrm{~d}$ \\
\hline glucose & $3.5 \pm 0.2 c$ & $49.7 \pm 3.3 \mathrm{a}$ & $23.3 \pm 0.1 b$ & $0.7 \pm 0.1 \mathrm{c}$ \\
\hline xylose & $273 \pm 3 b$ & $56.0 \pm 3.5 \mathrm{~d}$ & $207 \pm 14 c$ & $322 \pm 7 a$ \\
\hline galacturonic acid & $335 \pm 16 \mathrm{ab}$ & $196 \pm 22 c$ & $310 \pm 12 b$ & $378 \pm 12 a$ \\
\hline
\end{tabular}

${ }^{a}$ Different letters $\mathrm{a}-\mathrm{d}$ in the same row indicate significantly different levels of the monosaccharides in the raw material and the fractions $(p<0.05)$. ${ }^{b}$ Starting material.

05, DGCC 9917), Bifidobacterium lactis (HN019, DGCC2013), and Clostridium perfringens (ATCC 13124). These strains were incubated in liquid monocultures at $1 \%(\mathrm{v} / \mathrm{v})$ cell suspensions with each of the individual substrates at a final concentration of $1 \%(\mathrm{w} / \mathrm{v})$ in a glucosefree MRS-medium base (de Man, Rogosa, and Sharpe medium without glucose) in designated microtiter plates in a Bioscreen $\mathrm{C}$ system (Labsystems, Helsinki, Finland) and incubated anaerobically as described previously. ${ }^{25}$ Prior to the growth tests, the dissolved substrate solutions were sterilized (in $10 \% \mathrm{w} / \mathrm{v}$ solutions) by UV radiation for $3 \mathrm{~min}$. Anaerobic growth was measured by monitoring the increase of the biomass by optical density measurement (because the growth in the liquid cultures did not lend itself to cell count) and expressed as the calculated area under the growth curves, measured at $600 \mathrm{~nm}\left(\mathrm{OD}_{600}\right)$, using Biolink software (Labsystems) according to the protocol detailed in ref 25 . The baseline growth in the glucose-free MRS medium without addition of carbohydrates was used as the blank control, and the growth obtained was subtracted from the growth data obtained in the presence of substrate. Galactan from potato (Megazyme International Ltd., Bray, Co. Wicklow, Ireland) was used as an established prebiotic standard control. The experiments were done in three replicates for each strain and carbohydrate substrate. Data are given as mean values \pm standard error.

Statistical and Data Analysis. Reported data are given as average values determined after a minimum of duplicate determination. Data were analyzed by one-way analysis of variance (one-way ANOVA): Comparisons of mean values were calculated via $95 \%$ confidence intervals and compared as Tukey-Kramer intervals calculated from pooled standard deviations (Minitab Statistical Software, AddisonWesley, Reading, MA, USA).

\section{RESULTS AND DISCUSSION}

Enzymatically Produced Gum Tragacanth Polysaccharides. Modification of the selected, highly fucosylated, gum tragacanth with the Pectinex enzyme preparation was established to produce potentially prebiotic poly- and oligosaccharides having different molecular sizes. The enzyme treatment caused a sharp (50\%) decrease in viscosity within 10 min (data not shown), indicating the depolymerization of the gum tragacanth sample. The enzymatic reaction products were separated by membranes with 10 and $2 \mathrm{kDa}$ to get three fractions (yields given in parentheses as dry matter weight/ weight of the starting material): HAG1 $<2 \mathrm{kDa}$ (yield $\sim 10 \%$ $\mathrm{w} / \mathrm{w}) ; 2 \mathrm{kDa}<\mathrm{HAG} 2<10 \mathrm{kDa}(\sim 23 \% \mathrm{w} / \mathrm{w}) ;$ HAG3 > 10 $\mathrm{kDa}(\sim 67 \% \mathrm{w} / \mathrm{w})$. HPSEC analyses confirmed the depolymerization of the gum into different molecular weight fractions and revealed that the average size of the high molecular weight fraction population, HAG3, was approximately $110 \mathrm{kDa}$ (Figure 1). By a rough estimate, the HAG3 fraction thus contained branched polysaccharides having degrees of polymerization (DP) of 600-650 monosaccharides; the HAG2 polysaccharides were DP $\sim 12-60$, whereas the HAG1 fraction contained 
oligomers of maximum 10-12 DP. The HPSEC also indicated that there were no free monosaccharides in any of the three fractions (Figure 1), and this was also confirmed by HPAEC analysis (data not shown). The monosaccharide composition of the three fractions turned out to vary significantly and to differ from the starting material (Table 1). The data confirmed the dominance of galacturonic acid, xylose, and fucose in the starting material (Table 1). The high molecular weight fraction (HAG3) in essence became enriched in fucose during the enzymatic depolymerization, with the final product containing almost $300 \mathrm{mg}$ fucose/g dry matter (Table 1). This fraction, HAG3, was also rich in galacturonic acid and xylose, $~ 380$ and $320 \mathrm{mg} / \mathrm{g}$, respectively (Table 1). This result agrees with the expected attack pattern of the pectinases, because the pectinases are not able to attack the substituted fuco-xylogalacturonic acid structures. Apparently, the enzymatic degradation thus depleted the gum tragacanth polysaccharides in rhamnose, arabinose, galactose, and glucose, which is in accord with previous findings that have indicated that, in addition to polygalacturonase and pectin lyase, the enzyme preparation contains side activities that can catalyze the cleavage of several different kinds of bonds in complex plant cell wall structures. ${ }^{19}$ Analogously, the smaller fractions, HAG1 and HAG2, became very rich in arabinose and galactose; hence, the arabinose content was $293 \mathrm{mg} / \mathrm{g}$ in HAG1, $130 \mathrm{mg} / \mathrm{g}$ in HAG2, and $30 \mathrm{mg} / \mathrm{g}$ in HAG3, but HAG1 and HAG2 had significantly lower fucose and xylose contents than HAG3 (Table 1). The level of galacturonic acid was high in all three enzymatically treated fractions, ranging from 196 to $380 \mathrm{mg} / \mathrm{g}$, but lowest in HAG1 (196 mg/g) (Table 1). The enzymatic process thus seemed to cleave the pectin-resembling, polygalacturonic acid parts of the gum tragacanth polysaccharide backbone(s), apparently leaving the suspected xylogalacturonan, and especially the fuco-xylo-galacturonan, stretches in the gum tragacanth intact, that is, left in the HAG3 fraction. Hence, the enzymatic deconstruction using the pectinase in combination with membrane separation produced three significantly different gum tragacanth polysaccharide fractions with respect to both molecular size and composition.

Linkage Analysis. The linkage analysis confirmed the dominance of terminally linked fucose and (1),2-linked xylose, as well as terminally linked xylose in HAG3 and, to a lesser extent, in HAG2 (Tables 2 and 3). Taken together with the high galacturonic acid content (Table 1), these findings underscored that HAG3 and HAG2 contained the typical fuco-xylo-galacturonan structural elements of gum tragacanth first discovered by Aspinall and Baillie. ${ }^{26}$ However, despite the activation and prereduction of the uronic acids in the samples, the peak areas obtained for the uronic acid alditol acetates by the GC-MS analyses were relatively low (Table 2). In general, the frequency of the gum tragacanth hallmark fucose and xylose linkages were lower in HAG2 than in HAG3, whereas the (1),4-galactose linkages, and notably the (1),2,4-rhamnose linkages, were higher in HAG2 than in HAG3. The presence of these latter linkages in HAG2 appeared to indicate enrichment of rhamnogalacturonan 1-galactan-like structures in HAG2, a trend that became more evident in HAG1. In HAG1, the frequency of the 1,4-linked galactose bonds was dominating (Table 2); we presume that these bonds are due to the presence of $\beta 1$,4-linked galactan structural elements (Table 3 ) and galactan oligomers such as $\beta$-Galp- $(1 \rightarrow 4)-[\beta$-Gal $p-(1 \rightarrow$ $4)]_{2}$-Gal $p$ and $\beta$-Gal $p-(1 \rightarrow 4)-\beta$-Gal $p-(1 \rightarrow 4)$-Gal $p$ that presumably correspond to arabinogalactan-derived galactan, which is in
Table 2. Glycosidic Linkage Analysis of Different Gum Tragacanth Fractions of Different Molecular Sizes (HAG1 < $2 \mathrm{kDa}$; $2 \mathrm{kDa}<\mathrm{HAG} 2$ < $10 \mathrm{kDa}$; and HAG3 > $10 \mathrm{kDa})$, Obtained after Enzymatic Modification and Membrane Separation $^{a}$

\begin{tabular}{|c|c|c|c|c|}
\hline \multirow[b]{2}{*}{ monosaccharide } & \multicolumn{2}{|c|}{ HAG1 } & \multirow{2}{*}{$\frac{\text { HAG2 }}{\% \text { peak area }}$} & \multirow{2}{*}{$\begin{array}{c}\text { HAG3 } \\
\text { \% peak area }\end{array}$} \\
\hline & $\begin{array}{l}\text { linkage } \\
\text { type }\end{array}$ & $\%$ peak area & & \\
\hline \multirow[t]{5}{*}{ L-fucose } & $\mathrm{t}-\mathrm{Fuc} p$ & & $14.4(80.4)$ & $41.6(88.1)$ \\
\hline & 1,3-Fucp & & $0.8(4.5)$ & $1.2(2.6)$ \\
\hline & 1,4-Fucp & & $0.7(3.9)$ & $1.1(2.3)$ \\
\hline & 1,2-Fucp & & $1.7(9.5)$ & $2.8(5.9)$ \\
\hline & 1,3,4-Fucp & & $0.3(1.7)$ & $0.5(1.1)$ \\
\hline \multirow[t]{3}{*}{ L-rhamnose } & t-Rhap & & $0.2(1.4)$ & \\
\hline & 1,2,4 Rhap & $2.3(100)$ & $6.9(48.6)$ & \\
\hline & 1,4 Rhap & & $7.1(50)$ & \\
\hline \multirow[t]{2}{*}{ L-arabinose } & $\mathrm{t}$-Araf & $0.4(5.8)$ & $0.8(53.3)$ & $1.2(100)$ \\
\hline & 1,5 Araf & $6.5(94.2)$ & $0.7(46.7)$ & \\
\hline \multirow[t]{4}{*}{ D-galactose } & $\mathrm{t}-\mathrm{Gal} p$ & $3.7(5.6)$ & $3.7(20.2)$ & $1.6(88.9)$ \\
\hline & 1,4-Galp & $58.8(88.7)$ & $13.5(73.8)$ & $0.2(11.1)$ \\
\hline & $1,6 \mathrm{Gal} p$ & & $0.8(4.4)$ & \\
\hline & $1,4,6 \mathrm{Gal} p$ & $3.8(5.7)$ & $0.3(1.6)$ & \\
\hline \multirow[t]{3}{*}{ D-glucose } & t-Glup & $2.8(18.6)$ & $2.6(40.6)$ & $1.1(47.8)$ \\
\hline & 1,4-Glup & $8.5(56.3)$ & $3.5(54.7)$ & $1.2(52.2)$ \\
\hline & 1,2,4-Glup & $3.8(25.1)$ & $0.3(4.7)$ & \\
\hline \multirow[t]{3}{*}{ D-xylose } & $\mathrm{t}-\mathrm{Xyl} p$ & & $5.4(22.6)$ & $7.4(15.8)$ \\
\hline & 1,2,-Xylp & & $18.5(77.4)$ & $38.3(81.7)$ \\
\hline & 1,2,3-Xylp & & & $1.2(2.5)$ \\
\hline \multirow{3}{*}{$\begin{array}{l}\text { D-galacturonic } \\
\text { acid }\end{array}$} & $\mathrm{t}-\mathrm{GalA} p$ & $0.2(2.9)$ & $2.8(24.6)$ & $0.2(20)$ \\
\hline & 1,4-GalA & $6.6(97.1)$ & $8.5(74.6)$ & $0.8(80)$ \\
\hline & 1,4,6-GalA & & $0.1(0.9)$ & \\
\hline
\end{tabular}

${ }^{a}$ The values are semiquantitative and based on percent peak area. The values in parentheses indicate the relative abundance of the type of bond for the particular monosaccharide quantified from the peak area in the glycosidic linkage chromatography profile.

agreement with previous interpretations. ${ }^{12}$ In addition to the possible presence of $\beta$-bonded glucan and galactan structures, for example, $\beta$-Glcp- $(1 \rightarrow 4)-[\beta \text {-Gal } p \text { - }(1 \rightarrow 4)]_{2}$-Gal $p$ structures, that have been proposed previously to be present in gum tragacanth, ${ }^{12}$ the presence of 4-glucose linkages in all three fractions (Tables 2 and 3), HAG1, HAG2, and HAG3, also indicated the presence of $1,4-\beta$-glucan structures and/or starch oligomers, which is in accordance with the comprehension that gum tragacanth may contain some cellulose and starch elements. ${ }^{27}$ With regard to the high arabinose levels in HAG1 and HAG2 (Table 1), the linkage analysis demonstrated that the gum fractions contained mainly 1,5 and terminally linked arabinoses, which is in accordance with the presence of side-chain structures with $\alpha$-Araf and Arap in arabinogalactan, and short stretches of $1,5-\alpha$-bonded arabinan. The results thus indicated that the lower molecular weight oligosaccharides were rich in arabino-galactan and also contained short galacturonic acid stretches.

Growth of Pure Strains on Tragacanth Fractions. The growth of the strains in single cultures varied for all three gum 
Table 3. Illustration of the Presumed Major Bond Chemistries of Structural Unit Pairs of the Most Abundant Monosaccharides in the Different Gum Tragacanth Fractions of Different Molecular Sizes (HAG1 < 2 kDa; 2 kDa < HAG2 < 10 kDa; and HAG3 $>10 \mathrm{kDa}$ ) Deduced from the Compositional Analysis in Table 1 and the Semiquantitative Glycosidic Linkage Analysis Data Given in Table 2

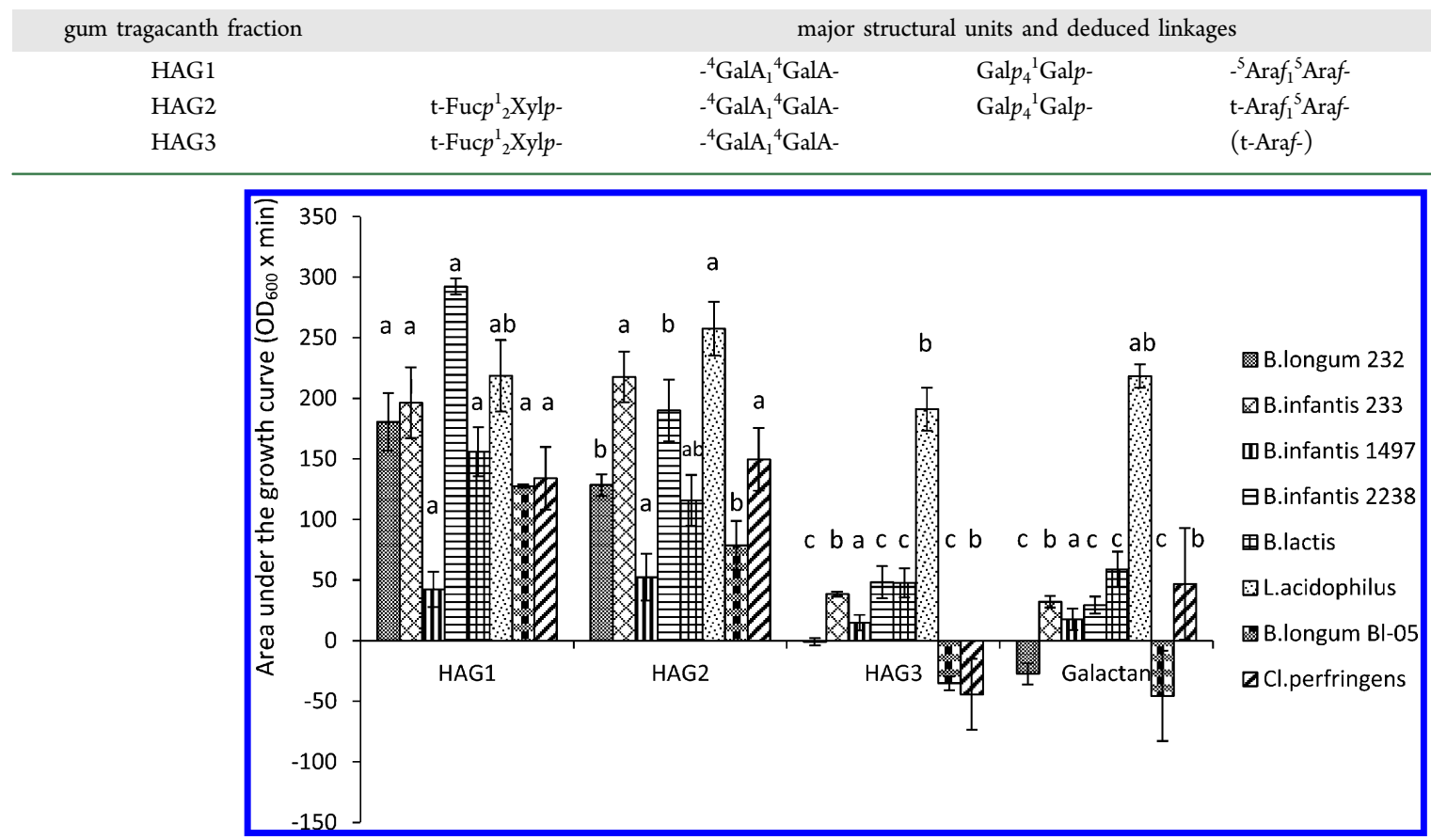

Figure 2. Differential growth of bacterial strains on enzymatically produced gum tragacanth samples of different molecular size fractions (HAG1 $<2$ $\mathrm{kDa} ; 2 \mathrm{kDa}<\mathrm{HAG} 2<10 \mathrm{kDa}$; and HAG3 $>10 \mathrm{kDa}$ ), obtained after enzymatic modification and membrane separation, against potato galactan used as control. Growth responses for the four substrates are shown for a substrate concentration of $10 \mathrm{~g} / \mathrm{L}$ for all bacterial strains. Data are expressed as calculated area under the growth curve $\left(\mathrm{OD}_{600 \mathrm{~nm}} \cdot \mathrm{min}\right)^{24}$ as average values of three growth assay replicates and shown \pm SD. Different roman letters $a-c$ above columns indicate statistically significant growth $(p<0.05)$ of the particular strain on the different substrates. For the one-way ANOVA of the bacterial growth the pooled SDs were B.longum subsp. longum (DGCC 232), 14.11; B. longum subsp. infantis (DGCC 233), 19.46; B. longum subsp. infantis (DGCC 1497), 10.67; B. longum subsp. infantis (DGCC 2238), 15.15; L. acidophilus (NCFM, ATCC 700396), 21.03; B. longum subsp. longum (Bl-05, DGCC 9917), 19.46; B. lactis (HN019, DGCC2013), 17.99; and C. perfringens (ATCC 13124), 30.72. For the total ANOVA (level, 32) the pooled SD was 18.75 .

tragacanth fractions, HAG1, HAG2, and HAG3, and the growth responses also differed from those on pure galactan used as control (Figure 2). The highest growth response was observed for B. longum subsp. infantis (DGCC 2238) on the HAG1 fraction $<2 \mathrm{kDa}$ (Figure 2). There was a significantly increasing growth in response $(p<0.05)$ to lowering of the molecular weight of the gum tragacanth samples for both of the B. longum subsp. longum strains (DGCC 232 and B1-05, DGCC 9917), for the B. longum subsp. infantis strain DGCC 2238, and for the $B$. lactis strain, whereas the growth of the B. longum subsp. infantis strain DGCC 233 was equally good on HAG1 and HAG2, but still lower on HAG3 (Figure 2.). The growth profile results for the HAG2 gum tragacanth fraction, which had molecular size of $2-10 \mathrm{kDa}$, were similar to those obtained on HAG1. The growth of the B. longum subsp. longum strain B105, DGCC 9917, was suppressed by the HAG3 as well as the galactan (Figure 2).

The HAG1 and HAG2 thus generally produced higher growth responses than galactan, the only exception being for $L$. acidophilus, which grew equally well on all three gum tragacanth fractions and on galactan (Figure 2). Although the HAG3 fraction, having a molecular weight $>10 \mathrm{kDa}$, was less metabolized by the majority of the strains, the growth responses obtained for HAG3 were the same as those on galactan, that is, there were no significantly different effects $(P>$
0.05 ) between these two substrates, except for the C. perfringens growth, which was suppressed by HAG3. Hence, C. perfringens used as a pathogenic control did not grow at all on the HAG3 fraction, but was able to grow (and grew equally well) on the HAG1 and HAG2 fractions and on the galactan.

Discussion. The stimulation by prebiotic carbohydrates of specific, probiotic, colonic bacteria is explained by the capability of these bacteria to degrade the glycosidic bonds in the putative, prebiotic carbohydrates and metabolize at least some of the saccharide components. This growth stimulation may provide a selective advantage when competing with other bacterial species in the mixed bacterial community prevailing in the human colon. The glycosidic bonds, the molecular size, and the monosaccharide composition of the prebiotic carbohydrates thus define the effect and the eventual relative increase in beneficial bacteria, including certain Bifidobacterium and Lactobacillus species. Gum tragacanth contains some unique substituted saccharides, notably the higly substituted fuco-xylogalacturonan and the arabinogalactan structures. As well, the long use of gum tragacanth in foods, albeit in low concentrations due to the marked viscosity effects, would indicate that the human gut microflora might be able to "recognize" this natural gum and possess genes encoding enzymes that can degrade the structural elements in this gum. The sequencing of the genome of $B$. longum subsp. infantis 
(ATCC15697), considered to be "the archetypical" human milk oligosaccharide utilizing bacterium, has thus shown that the genome possesses a large $(43 \mathrm{kbp})$ gene cluster within which several specific glycosyl hydrolase encoding genes are located, including a fucosidase encoding gene. ${ }^{28}$ It has also recently been demonstrated that $B$. longum subsp. infantis (ATCC15697) will proliferate on human milk oligosaccharides, $^{29}$ and mass spectrometry-based glycoprofiling of this oligosaccharide consumption has revealed that $B$. longum subsp. infantis appears to exhibit a specific preference for fucosylated oligosaccharides. ${ }^{28}$

However, because human milk oligosaccharides are highly diverse structurally, it is premature to conclude that terminal fucosyl residues in human milk oligosaccharides contribute significantly to their prebiotic properties, and, as yet, no specific relations between the microbial consumption, the saccharide structures, linkages, and, for example, fucosyl substitutions have been proven unequivocally.

The present work was exclusively aimed at assessing the possible growth stimulation effects on selected gut-relevant bacteria of gum tragacanth-derived compounds as a first line of evidence prior to initiating further evaluations of the influence of these compounds on metabolic responses and response mechanisms on gut-related microbial communities.

In the present work, to provide for a measurable response and to test the hypothesis that gum tragacanth saccharides might be bifidogenic and potentially prebiotic in a wider sense, the viscosity of the gum had to be lowered to enable the supply of higher dosages of the gum saccharides. Pectinase-assisted degradation provided a route to retain the unique fuco-xylogalacturonans as well as the xylo-galacturonans, and partly the available arabinogalactans, while at the same time cause a lowering of the viscosity. The data obtained confirmed that the gum tragacanth could be processed into differently sized polyand oligosaccharide fractions via the enzymatic treatment and membrane purification. The size of the tragacanth gum oligomers had an impact upon the growth of prebiotic bacteria, whereby a lower molecular size (HAG1), of an estimated DP of $10-12$, as well as the HAG2, of DP $\sim 12-60$, coinciding with the compounds being richer in arabino-galactans, supported a much higher growth than the significantly higher molecular weight fuco-xylo-galacturonans (HAG3) (Figure 2).

The putative fucosidase activity of the selected $B$. longum subsp. infantis was expected to be induced and allow these bacteria to grow on the HAG3. However, the highly fucosesubstituted xylo-galacturonans did not support the growth of prebiotics to the extent expected; despite the relatively modest growth, the three different $B$. longum subsp. infantis strains responded significantly differently, with the $B$. longum subsp. infantis strain DGCC 1497 growing significantly less $(P<0.05)$ than the two other infantis strains, but significantly more $(P<$ 0.05 ) than both of the tested $B$. longum subsp. longum strains (Figure 2). We ascribe the general low growth on HAG3 as most likely being due to the large molecular size of these polysaccharides (Figure 1), but the differential response of the $B$. longum subsp. infantis strains may be related to differences in the expression of fucosidase activity by these strains, whereas the lack of response of the B. longum subsp. longum growth may indicate a deficiency in fucosidase encoding genes. Nevertheless, the results clearly confirmed that the molecular size, structure, and type of linkages of the enzymatically produced gum tragacanth polysaccharides affected their prebiotic potential.
In conclusion, the results showed that enzymatically produced, oligomeric structures from gum tragacanth had potential prebiotic activity. The data obtained with singleculture fermentations in vitro obviously do not fully reflect the events occurring in vivo in the gut. Nevertheless, the results do provide a first positive indication that gum tragacanth may be a source of functional poly- and oligosaccharides that may exert beneficial bioactivity as prebiotics. The data therefore form a first-decision base to develop further studies of the possible prebiotic potency of these components in a complex microbial flora environment and eventually further by evaluations in animal and human trials. The eventual application of enzymatically hydrolyzed gum tragacanth oligomers in foods requires further work to define relevant dosage levels and assess and minimize interactions of the gum tragacanth oligomers with other food components (e.g., proteins). The application of these oligomers in foods would be a new, value-added application of a classic food gum.

\section{AUTHOR INFORMATION}

\section{Corresponding Author}

*Phone: +45 4525 2800. Fax: +45 4588 2258. E-mail: am@kt. dtu.dk.

\section{Funding}

We acknowledge Tarbiat Modares University and the Ministry of Science, Research and Technology of Iran for their financial support. This work was also partially financed by the Danish Strategic Research Council's Committee on Food and Health (FøSu, Project "Biological Production of Dietary Fibers and Prebiotics”, no. 2101-06-0067).

\section{Notes}

The authors declare no competing financial interest.

\section{REFERENCES}

(1) Gibson, G. R; Roberfroid, M. B. Dietary modulation of the human colonic microbiota: introducing the concept of prebiotics. $J$. Nutr. 1995, 125, 1401-1412.

(2) Roberfroid, M. Prebiotics: the concept revisited. J. Nutr. 2007, 137, 830S-837S.

(3) Bode, L. Human milk oligosaccharides: every baby needs a sugar mama. Glycobiology 2012, 22, 1147-1162.

(4) Gopal, P. K.; Sullivan, P. A.; Smart, J. B. Utilisation of galactooligosaccharides as selective substrates for growth by lactic acid bacteria including Bifidobacterium lactis DR10 and Lactobacillus rhamnosus DR20. Int. Dairy J. 2001, 11, 19-25.

(5) Roberfroid, M. B.; Van Loo, J. A. E.; Gibson, G. R. The bifidogenic nature of chicory inulin and its hydrolysis products. J. Nutr. 1998, 128, 11-19.

(6) Mountzouris, K. C.; Gilmour, S. G.; Rastall, R. A. Continuous production of oligodextrans via controlled hydrolysis of dextran in an enzyme membrane reactor. J. Food Sci. 2002, 67, 1767-1771.

(7) U.S. Food and Drug Administration, available at http://www.gpo. gov/fdsys/pkg/CFR-2011-title21-vol3/pdf/CFR-2011-title21-vol3sec184-1355.pdf (accessed Nov 6, 2012).

(8) Gavlighi, H. A.; Meyer, A. S.; Zaidel, D. N. A.; Mohammadifar, M. A.; Mikkelsen, J. D. Stabilization of emulsions by gum tragacanth (Astragalus spp.) correlates to the galacturonic acid content and methoxylation degree of the gum. Food Hydrocolloids 2013, 31, 5-14.

(9) Whistler, R. L. Industrial Gums: Polysaccharides and Their Derivatives; Academic: New York, 1993.

(10) Balaghi, S.; Mohammadifar, M. A.; Zargaraan, A. Physicochemical and rheological characterization of gum tragacanth exudates from six species of Iranian Astragalus. Food Biophys. 2010, 5, 59-71.

(11) Balaghi, S.; Mohammadifar, M. A.; Zargaraan, A.; Gavlighi, H. A.; Mohammadi, M. Compositional analysis and rheological character- 
ization of gum tragacanth exudates from six species of Iranian. Food Hydrocolloids 2011, 25, 1775-1784.

(12) Tischer, C. A.; Iacomini, M.; Gorin, P. A. J. Structure of the arabinogalactan from gum tragacanth (Astralagus gummifer). Carbohydr. Res. 2002, 337, 1647-1655.

(13) Al-Tamimi, M.; Palframan, R.; Cooper, J.; Gibson, G.; Rastall, R. In vitro fermentation of sugar beet arabinan and arabinooligosaccharides by the human gut microflora. J. Appl. Microbiol. 2006, 100, 407-414.

(14) Thomassen, L. V.; Vigsnæs, L. K.; Licht, T. R.; Mikkelsen, J. D.; Meyer, A. S. Maximal release of highly bifidogenic soluble dietary fibers from industrial potato pulp by minimal enzymatic treatment. Appl. Microbiol. Biotechnol. 2011, 90, 873-884.

(15) Michalak, M.; Thomassen, L. V.; Roytio, H.; Ouwehand, A. C.; Meyer, A. S.; Mikkelsen, J. D. Expression and characterization of an endo-1,4- $\beta$-galactanase from Emericella nidulans in Pichia pastoris for enzymatic design of potentially prebiotic oligosaccharides from potato galactans. Enzyme Microb. Technol. 2011, 50, 121-129.

(16) Olano-Martin, E.; Mountzouris, K. C.; Gibson, G. R.; Rastall, R. A. Continuous production of pectic oligosaccharides in an enzyme membrane reactor. J. Food Sci. 2001, 66, 966-971.

(17) Pinelo, M.; Jonsson, G.; Meyer, A. S. Membrane technology for purification of enzymatically produced oligosaccharides: molecular and operational features affecting performance. Sep. Purif. Technol. 2009, $70,1-11$.

(18) Holck, J.; Hjernø, K.; Lorentzen, A.; Vigsnæs, L. K.; Hemmingsen, L.; Licht, T. R.; Mikkelsen, J. D.; Meyer, A. S. Tailored enzymatic production of oligosaccharides from sugar beet pectin and evidence of differential effects of a single DP chain length difference on human faecal microbiota composition after in vitro fermentation. Process Biochem. 2011, 46, 1039-1049.

(19) Arnous, A.; Meyer, A. S. Discriminated release of phenolic substances from red wine grape skins (Vitis vinifera L.) by multicomponent enzymes treatment. Biochem. Eng. J. 2010, 49, 68-77.

(20) Arnous, A.; Meyer, A. S. Comparison of methods for compositional characterization of grape (Vitis vinifera L.) and apple (Malus domestica) skins. Food Bioprod. Process 2008, 86, 79-86.

(21) Rasmussen, L. E.; Meyer, A. S. Size exclusion chromatography for the quantitative profiling of the enzyme-catalyzed hydrolysis of xylo-oligosaccharides. J. Agric. Food Chem. 2009, 58, 762-769.

(22) Kim, J.-B.; Carpita, N. C. Changes in esterification of the uronic acid groups of cell wall polysaccharides during elongation of maize coleoptiles. Plant Physiol. 1992, 98, 646-553.

(23) Ciucanu, I.; Kerek, F. A simple and rapid method for the permethylation of carbohydrates. Carbohydr. Res. 1984, 131, 209-217.

(24) York, W. S.; Darvill, A. G.; McNeil, M.; Stevenson, T. T.; Albersheim, P. Isolation and characterization of plant cell walls and cell wall components. In Methods in Enzymology; Weissbach, A., Weissbach, H., Eds.; Academic Press: New York, 1986; Vol. 118, pp 3-40.

(25) Mäkeläinen, H.; Saarinen, M.; Stowell, J.; Rautonen, N.; Ouwehand, A. Xylo-oligo-saccharides and lactitol promote the growth of Bifidobacterium lactis and Lactobacillus species in pure cultures. Benef. Microbes 2010, 1, 139-148.

(26) Aspinall, G. O.; Baillie, J. Gum tragacanth. Part I. Fractionation of the gum and the structure of tragacanthic acid. J. Chem. Soc. 1963, $1702-1714$.

(27) Glicksman, M. Utilization of natural polysaccharide gums in the food industry. In Advances in Food Research; Chichester, C. O., Mrak, E. M., Stewart, G. F., Eds.; Academic Press: New York, 1963; Vol. 11, pp 109-200.

(28) Sela, D.; Chapman, J.; Adeuya, A.; Kim, J.; Chen, F.; Whitehead, T.; Lapidus, A.; Rokhsar, D.; Lebrilla, C.; German, J. The genome sequence of Bifidobacterium longum subsp. infantis reveals adaptations for milk utilization within the infant microbiome. Proc. Natl. Acad. Sci. U.S.A. 2008, 105, 18964-18969.

(29) Marcobal, A.; Barboza, M.; Froehlich, J. W.; Block, D. E.; German, J. B.; Lebrilla, C. B.; Mills, D. A. Consumption of human milk oligosaccharides by gut-related microbes. J. Agric. Food Chem. 2010, $58,5334-5340$. 